\title{
TV/Series
}

$13 \mid 2018$

Diziler : les séries télévisées turques

\section{La liste des chaînes de télévision en Turquie et les acronymes utilisés dans ce recueil}

\section{OpenEdition}

Journals

Édition électronique

URL : http://journals.openedition.org/tvseries/2398

DOI : $10.4000 /$ tvseries.2398

ISSN : 2266-0909

Éditeur

GRIC - Groupe de recherche Identités et Cultures

Référence électronique

"La liste des chaînes de télévision en Turquie et les acronymes utilisés dans ce recueil », TV/Series [En ligne], 13 | 2018, mis en ligne le 03 juillet 2018, consulté le 23 septembre 2020. URL : http://

journals.openedition.org/tvseries/2398; DOI : https://doi.org/10.4000/tvseries.2398

Ce document a été généré automatiquement le 23 septembre 2020.

\section{(c) (†) $\odot$}

TV/Series est mis à disposition selon les termes de la licence Creative Commons Attribution - Pas d'Utilisation Commerciale - Pas de Modification 4.0 International. 


\section{La liste des chaînes de télévision en Turquie et les acronymes utilisés dans ce recueil}

\section{La liste des chaînes publiques et privées de la télévision turque}

NB : nous ne mentionnons pas les chaînes qui ont disparu

Les chaînes publiques

TRT 1

TRT 3

TRT Avaz

TRT Belgesel

TRT Haber

TRT Kurdî

TRT Türk

Les chaînes privées et satellitaires

ATV (Turquie)

BeIN Sports (Turquie)

Cartoon Network (Turquie)

CNN Türk

Disney Channel (Turquie)

Euro D

EuroStar TV

Fox (Turquie) - anciennement TGRT: Türkiye Gazetesi Radyo Televizyonu

Fox Life

Galatasaray TV 
Hayat TV

Kanal D

Kidz TV

MTV (Turquie)

NTV (Turquie)

Powertürk TV

Samanyolu TV

ShortsTV

Show TV

Star TV (Turquie)

TLC Türkiye

\section{Acronymes utilisés dans ce recueil}

AKP : Adalet ve Kalkınma Partisi, Parti de la justice et du développement, au pouvoir depuis 2001 en Turquie

DISCOP : équivalent du MIPCOM - marché de productions télévisuelles et cinématographiques - pour l'Afrique et le Moyen Orient.

EBU : European Broadcasting Union

LATAM : Latin American

MENA : Middle-East and North Africa

MIPCOM : Marché International des Programmes de Communication- réunion annuelle pour les professionnels de la télévision qui peuvent acheter des séries à diffuser sur leur chaîne.

NATPE : National Association of Television Program Executives

PKK : Parti des travailleurs du Kurdistan (Partiye Karkeren Kurdistan), groupe armé kurde

RTÜK : Radyo ve Televizyon Üst Kurulu, Conseil supérieur de l'audiovisuel.

YPG : Kurdish People's Protection Units (Yekîneyên Parastina Gel) 